\title{
AC 2010-8: USING LIBGUIDES AS A WEB 2.0 CONTENT MANAGEMENT SYSTEM AND A COLLABORATION TOOL FOR ENGINEERING LIBRARIANS
}

\section{Richard Bernier, Rose-Hulman Institute of Technology}

Richard Bernier is the Reference and Electronic Services Librarian at Rose-Hulman Institute of Technology where he manages subscriptions and access to all electronic resources; conducts reference service and library instruction, and manages the digital archives project. He is currently transitioning his library toward a Library 2.0 environment. 


\title{
Using LibGuides as a Web 2.0 Content Management System and a Collaboration Tool for Engineering Librarians
}

\begin{abstract}
With the implementation of the most widely used research guide platform LibGuides, librarians can adopt a Library 2.0 presence with minimal effort at a reasonable cost. This paper will discuss how this content management system integrates a multitude of Web 2.0 features, allowing librarians to create an interactive research environment with their users. LibGuides can also serve as a communication portal between engineering librarians and as an effective resource sharing tool. Springshare, the maker of LibGuides, has created several methods of promoting resource sharing, including the "LibGuides Community," the "Springshare Lounge," and a blog where Springshare employees can share the latest news about LibGuides and their other products. Although lacking some of the Web 2.0 components like end-user accounts, thus preventing it from being a full-blown Web 2.0 system, LibGuides does much to bridge the gap between a static Library 1.0 website and a Library 2.0 website.
\end{abstract}

\section{Introduction}

For several years, librarians have been using piecemeal approaches to create a Library 2.0 presence. This has been done by adding Web 2.0 applications such as wikis, RSS feeds, blogs, and chat services, on top of static web pages on their library web site. Various other platforms have been experimented with such as wikis and content management systems such as Joomla. Both of these types of open source systems have a number of drawbacks. For instance, wikis are quite limited in how information that can be presented and content management systems like Joomla can be very complicated to configure and customize to use as a library research guide. Neither types are designed specifically to present library resources to patrons in an organized way and lack many features that librarians would like to have integrated into their guides.

Few would argue with the notion that a library website's main purpose is still to systematically organize and present to their user base, both paid and free information resources. The answer is 
subject guide systems designed specifically for libraries. The two most widely used products are LibGuides and Subjects Plus. LibGuides is a commercial product hosted by SpringShare. SubjectsPlus is a free open source product that was designed by Ithaca College Library. Both have similar features such as the ability to organize any type of information, integrate videos, podcasts, images, and other types of dynamic content. Although SubjectsPlus is free, it is open source and will likely require a programmer or proper technical staff to install, configure, and maintain the system. Since LibGuides is hosted by a commercial vendor, it requires no server or database maintenance and its configuration can be done by almost anyone. LibGuides' cost is reasonable with pricing based on the size of an institution. Without disclosing specific costs, my small library was able to subscribe to LibGuides during a time of fiscal austerity when our budget was being squeezed from several different directions. Another benefit of LibGuides over SubjectsPlus is the number of institutions using each. As of March 2010, LibGuides listed 1,113 libraries worldwide using this resource with 76,596 guides while SubjectsPlus only had twentyfour libraries listed on their website as users of their system. The LibGuides Community and built-in resource discovery mechanism is a major benefit for librarians looking for a simple way to manage their information resources.

LibGuides is a robust content management system containing a variety of integrated Web 2.0 services designed specifically for libraries. By integrating these services with the library's information resources' points of access, librarians can create an environment that allows users to interact directly with the library staff. Librarians can also monitor usage statistics at various levels of granularity, which provides information about library usage beyond traditional database statistics. For instance, while we may know that a particular database has been accessed X number of times, through LibGuides statistics, we can see how they are accessing it and are able to learn a little bit more about their research steps. As a subscriber to LibGuides, librarians also have the ability to become a part of a LibGuides social network, a combination of three different services geared towards allowing worldwide librarians to cooperate in their LibGuides endeavors. The community consists of the LibGuides Community: a platform for librarians to draw upon the guides of other libraries; the Springshare Lounge: a social networking website for LibGuides users; and a staff-run support blog for Springshare administrators to relay important information to their member librarians. By upgrading to Springshare's other major product, 
CampusGuides, this gap can be closed even further. With three levels of user accounts, endusers can create their own accounts and their own guides.

\section{What is Library 2.0?}

A Library 2.0 service has been defined by Michael Casey and Laura Savastinuk as "any service, physical or virtual, that successfully reaches users, is evaluated frequently, and makes use of customer input."1 Casey has been credited with coining the phrase "Library 2.0" when he launched his blog LibraryCrunch in September of $2005^{2}$ and since then the concept has gained a great deal of attention. Central to this concept is the integration of Web 2.0 services into traditional library websites to harvest the collective intelligence of everyone who uses a product. Thus, the flow of information is two-way, allowing end-users to contribute to the knowledge base for other users to access. Library 2.0 switches from relying on the stagnant Web 1.0 to the user driven, participatory, and personalized Web 2.0. Web 2.0 services allow a "read/write" environment for users because easy to use tools allow them to collaborate in the sharing and creation of content. ${ }^{3}$ Although many librarians and scholars may scoff at the notion of their users creating content, let's first examine exactly what this means and what the implications are for libraries.

Content creation in this context does not refer to the type of scholarly resources like journal articles users are searching for when they turn to the library website. Librarians still have to evaluate, select and make available quality commercial and free resources to their users. Instead, it refers to allowing a two-way flow of information between user and librarian as well as between different librarians. This could come in several ways including:

- How information resources are presented

- Ability of users to interact with content through the use of resource ratings, comments, and link submissions - feedback which allows greater librarian monitoring of user's needs - Ability to connect with librarians immediately at the point of need - reference options are always visible

- Collaboration between librarians 
By adding this online communication and feedback mechanism, librarians are not left to make assumptions about their user's needs and the best information resources based on their own empirical knowledge base. Operating in a Library 1.0 environment, these assumptions are based on other forms of static feedback such as Interlibrary loan requests and database usage statistics. Through Web 2.0 communication and interaction, librarians can gain a greater understanding of what their users are thinking. For example, lower database statistics and/or Interlibrary loan requests do not indicate if users are finding better resources elsewhere, or where they are finding them. User feedback and resource suggestion options allow users to communicate their findings (or lack of) with librarians, thus allowing librarians to improve their services and resources. College students today are already operating in this environment and so the information portals that we painstakingly create for our users must be integrated into this Web 2.0 environment. LibGuides is first and foremost a resource manager. That being said, LibGuides allows librarians to organize their information resources in an environment that has Web 2.0 services merged directly into the subject classification schemas that librarians use. ${ }^{4}$

\section{How LibGuides Creates a Library 2.0 Environment}

\section{1) Collaborative Content Management System}

The system is hosted and maintained by Springshare and requires an annual fee. Information resources are organized into subject guides. Subject guides may be as broad as "Engineering," or narrower for specific subject areas such as "Electrical Engineering," or "Nanotechnology." Guides may even be set up to suit the needs of specific courses. User accounts can be set up for as many librarians or staff members as desired. This allows subject specialists to take ownership of the content they present to their users and organize it in a way that they think makes sense. Guide owners may designate other librarians as co-editors, allowing for collaboration between librarians in specific subject areas. Faculty members may also be given accounts at the discretion of the library staff to create course specific guides. The LibGuides interface is highly customizable, allowing librarians to match the look and feel of their own library web site. Customization can be set and locked system-wide, thus allowing individual librarians access to only certain customization features. This helps maintain a consistent look and feel throughout the site. 


\section{2) How Information is Organized}

Numerous types of information resources can be added to each page, which is broken up by different types of content boxes. The most basic type of content box is "Simple Web Links," a box of web links which displays a short description of a resource in a pop-up balloon as the cursor hovers over a link. Slightly more complex, "Links and Lists" enables librarians to create lists of web links and non-web link items, a short description below the link or list item, and a "more info" button that provides more detailed information about a resource in a pop-up balloon. The most versatile box type is the "Rich Text/Dynamic Content/Scripts" box which is for any type of formatted text including html, links, or dynamic javascript code. Custom scripts like iFrame can also be embedded. This type of information can also be entered into any of the other types of boxes by clicking the "add text" link at the top of each box. Other types of boxes include RSS feeds, podcasts feeds, embedded video, Del.icio.us Tag Clouds, books from the catalog, documents and files, and dates and events.

Each subject guide can be broken down into multiple tabs which contain different types of resources. Guides can be categorized into subject groupings and have subject tags applied to them. Users can choose to browse guides by subject, by tags, by "popular guides," or by guide author. They can also search across all guides. For example, searching for "standards" would bring up a results page that consisted of pages within guides that included standards.

\section{3) User Interaction}

User interaction comes in different forms. First, each box can be set to allow users to add comments about resources within that box, a feature that can be turned on or off by the system administrator. To avoid SPAM or inappropriate comments, comment approval can also be required by the guide's owner before they are posted live. Comments allow users to express their views on resources they found useful or not so useful, or to recommend additional resources. There is also the option to allow users to rate resources by clicking one of five stars. There is a specific type of content box that allows users to suggest links. Finally, interactive polls can be created that ask users to select an item from a multiple choice list. A sample question could be: "Which database do you find most useful when looking for articles in Electrical Engineering?" They could then select from a list of relevant pre-selected databases. 
Why is this type of feedback important? The ability for users to interact with the site and provide feedback is important for both the users and the librarians. Users need to know that they are a part of the learning environment. Attitudes that librarians are the ones with information gathering knowledge and that users must rely on them are antiquated and no longer works with the new generation of college students. Today's college students are living in a world of Google, Wikipedia, Amazon.com, and a multitude of other Web 2.0 services that allows them to be active participants in the information sharing process. They have a certain level of confidence in their ability to find the information they are looking for based on their experiences. It is often only when they have specific resource guidelines placed on them by their professors that they realize they need to use the library. Through trial and error, they discover that what works when searching Google, usually does not work when operating within the rigid confines of a structured database. But in order for librarians to reach them, we must do so in a technological environment that they are used to and we must show them that we value their feedback. As librarians, this feedback is important for us to understand how to best serve them. We cannot simply look at lower database usage and dwindling reference statistics and sit back and ask "Where are they? Why don't they come?" We must be proactive in engaging them on a number of levels including increased traditional bibliographic instruction and also through Web 2.0 interaction.

LibGuides allows librarians to create a library website with a face. Older traditional library websites often consisted of pages of resources listing databases and other resources by subject. Another element of the library website is a section about staff. Set off from the information resources, this page, or groups of pages, would list the staff members either alphabetically or by subject area. Thus, users would go to one place from the main library page to access information resources, and then to another place to find out who they can ask for help. In most situations, when a student needs help, they wait until they have time to stop by the library and ask for help. While face to face reference service is often the best means of providing help such as with complex research questions or literature searches, other times students may have a quick question such as what is the best database to search or how to find out if the library subscribes to a particular journal. These types of questions are perfect candidates for virtual reference. 
Libraries have experimented with various types of chat services including commercial chat reference services, often linked from one place on the library website. With this approach, there is a still a disconnect between the librarian and the user at their point of need. With LibGuides, each guide owner has a profile that they can customize to include contact information, a photograph, and a chat widget, allowing users to connect directly to the librarian who created that guide. While most librarians use a Meebo Chat widget to connect to the Instant messenger service of their choice, any messenger service that allows users to generate an embeddable chat widget into their profile can be used. With chat widgets, whenever the librarian is logged into their chat service, the chat widget will show that they are online and available. As soon as they $\log$ off, their status changes to logged off. Thus, users can connect directly to a librarian at the point of need for immediate assistance. The profile also puts a human face to the organization of information resources that they are using. It is crucial that users know the identity of the librarian in which they are interacting. If they are unsatisfied with their experience using virtual

reference, they are unlikely to return. A non-productive experience with a faceless librarian may cause them to completely abandon the virtual reference option for the future. If there is a face attached to a session, they will use that first encounter to make a judgment as to whether they should consult with that librarian in the future just as they would in a face to face session. ${ }^{5}$ With other librarians available, they will have options for future virtual reference service. Thus, it is important for librarians to communicate with their users by getting their name and contact info, follow up on challenging reference questions, and collaborate with other librarians who can assist. "As technology progresses and users are increasingly able to find information for themselves online, it is increasingly important that digital reference services be able to provide answers to their users, or suffer the consequence that unsatisfied users may defect." 6 Librarians staff a reference desk so that users in the library can have one-on-one communication with them. Since librarians are providing them a virtual library via the Internet, they should also staff that virtual presence with a virtual identity of their own.

\section{LibGuides Community}

As managers of information resources, engineering librarians stand to gain from LibGuides beyond simply organizing their own web resources. By being a subscriber to LibGuides, librarians are members of the LibGuides Community. LibGuides currently has over 78,756 
guides by 18,386 librarians at 1,171 libraries worldwide (http://libguides.com/community for the most up-to-date numbers). While anyone can view any of these guides from this site, guide owners can copy guide links, boxes, pages, or entire guides directly into their own guide pages or account. While copying entire guides into their account might not be practical, exploring guides is a fantastic way for librarians to discover new resources for their collection and to seamlessly add it to any page of any of their guides. Librarians can browse or search across thousands of guides to see what other free and commercial resources other librarians are using. This is much more efficient than navigating through library websites of various colleges and universities with engineering programs with the hopes of discovering useful resources. If boxes, sections of guides, or complete guides are copied, proper etiquette suggest that credit should be given to the original guide's owner.

The Springshare Lounge is a social networking site for LibGuide users. Like all social networking sites, users can create a profile page for themselves and maintain a list of "friends," of other LibGuide users. Users also have access to their own blog. Blog posts show up on everyone's main page under the "Latest Activity" section in abbreviated form. Unlike Facebook status postings, blog post show up on everyone's pages and are meant for more substantive content than status updates. The Forum is a built-in platform where members can ask questions which can be answered by other members or LibGuide system administrators. Finally, Springshare has their own Support Blog and Twitter accounts which allows them to relay useful information to their members such as updates, fixes to problems, or useful tips and tricks.

\section{Missing Library 2.0 Components - Enter CampusGuides}

LibGuides is only one component of a Library 2.0 platform, as it offers some Web 2.0 capabilities already mentioned, but is still lacking in some other areas. The most obvious missing component is the ability for end-users to log-in to LibGuides and customize it to suit their needs. End-users can sign up for email alerts about new guides published, subscribe to RSS feeds, and post to the site, but they have no means of logging in and customizing it for their own use. When users think of a Web 2.0 service, they think of Amazon.com, Wikipedia, and social networking sites like Facebook where they have their own accounts, can save or bookmark relevant information, communicate with other users through their account, and have other 
resources suggested to them. The key concepts of Web 2.0 are participation and interaction. ${ }^{7}$ LibGuides integrates these concepts in a semi-interactive environment, but does not quite reach the level of a full blown Web 2.0 system.

For instance, LibGuides stands apart from some resources and other sharing tools such as next generation catalogues that allow user accounts, discovery tools that sit on top of catalogues, and federated search engines. While end-users are able to provide feedback and communicate with librarians, end-users are unable to create their own accounts to customize for their own needs, a major component to any Web 2.0 system. An obvious flaw to chat widgets is that librarians often have no idea who they are communicating with through chat widgets unless they ask for that information. If a student leaves the page with the chat widget and the connection is lost, the librarian is unable to continue the communication or to follow up on the reference request.

CampusGuides is an extended, more robust version of LibGuides. CampusGuides is designed for larger organizations or even consortiums. CampusGuides can be grouped in several different ways. For example, larger library systems can group guides by different libraries on campus. Guides in CampusGuides can also be grouped by academic departments, libraries within a consortium, or any other logical way that works for them. Each group can define its own look and feel with their own banners and headers. In CampusGuides there are three levels of accounts: administrators, librarians, and "other." "Other" can be defined as desired such as "faculty" or "student." Future enhancements will allow administrators to define rights and permissions of the other two types of accounts. Students authenticating from a specific IP address range will be able to create their own accounts and guides. Springshare is working on an e-Reserves module and exploring the possibility of using the system as a platform for students to create ePortfolios. ${ }^{8}$

\section{Personal Observations}

The library at Rose-Hulman Institute of Technology subscribed to LibGuides almost a year ago and certain observations should be noted in relation to some of the prior arguments put forth. First, it should be noted that since we have been subscribers for less than a year, our foray into LibGuides is still in its infancy and thus should not be viewed as concrete evidence for or against 
any of the suggested claims. Second, we are a small college with just under 2,000 students so experiences will differ between institutions of different types and sizes.

At time of publication, we had thirteen guides. In the first six months of use, the top five guides used are as follows:

1) "Logan Library Databases" - a list of all our subscribed databases in two tabs ("AtoZ List" and "By Subject"). - accessed 8,916 times

2) "Engineering (general)" - accessed 2,217 times

3) "Humanities and Social Sciences (general)" - accessed 1,376 times

4) "RH-330 Technical Communications and Professional Communication" (class specific guide) accessed - 936 times

5) “Applied Biology" - accessed 416 times.

These numbers indicate several things. First, that LibGuides is being heavily used by our students and the rest of our research community. Second, that our users most often use the "Logan Library Databases" guide which could mean a number of things. It could indicate that they know what database they want to use and know the quickest way to get to it. Or it could also indicate that they would prefer to navigate our databases by title alphabetically or by subject groupings on a single page. It is the author's opinion that it is a combination of the two, leaning more toward the former. This is based on the fact that when we conduct bibliographic instruction classes, we highlight databases that would be useful to that particular class. Therefore, they may already know what database they want to use. The numbers for the second and third mostly widely used guides are also quite high for a six month period. Since we only have thirteen guides and have not developed guides for each of the specific engineering and humanities \& social sciences disciplines, it would be natural for guides with such a wide cope, such as "Engineering," to have high usage. As we create more subject specific guides, we expect to see a shift in these numbers. Third, it is worth pointing out that the guide for the Technical Communications class has received high usage. This class has a crucial research component and in two academic quarters, these students have turned to this guide as a starting point in high numbers.

However, user feedback on the LibGuides website is low. We have not received any comments in the guide boxes. We also have not had any link suggestions although only a few guides have 
this feature added to it at this time. Our users have been using the rating feature in which they simply have to click from one to five stars to express what they think about the resource. The use of chat widgets has been quite successful as we expected. We knew there was a need for such a service since our database usage statistics show us that of all student research being conducted, approximately $41 \%$ is being conducted in the residence halls and Greek houses, $25 \%$ from the Virtual Private Network used by off campus users, 13\% from Wireless users (including inside library), and only $11 \%$ from inside the library via hard-wired Internet connections. ${ }^{9}$ Approximately one third of all reference questions have come from chat initiated requests in our first two academic quarters since we've implemented the option. Our students that are outside the library can see that we are online and available and have not hesitated to use the chat widget to ask questions. The two most typical questions we get are what database they should search for a particular topic and if we have access to a particular journal. Both questions lend themselves well to virtual reference and when they need more in-depth research assistance, we try to set up a time for them to come into the library to meet with us. Through our experience using chat widgets at the point of need; on each of the guides, we have fulfilled the need to provide students with answers to questions wherever they may be located at the time they need help. Finally, we have received many verbal compliments on the new system by both students and faculty. So although the LibGuides user interaction on the website may be inconclusive at this time, we can say with a certain level of certainty that it has been positively received and accepted by our users.

\section{Conclusion}

Library 2.0 is no longer just an abstract concept or the latest fad for librarians to explore. It is the environment in which our users are already conducting a large portion of their online lives. Ten years ago we redefined our definition of the library as a place that extends beyond the physical location. We crafted our services and resources to make them available online as our users expected. We are at a point where we must once again redefine how we will deliver our services. We must revise our web presence to create a library environment that our users expect. While much trial and error has gone into experimenting with various Web 2.0 services, it is now time to bring these together in a central location. LibGuides can be viewed as a starter Library

2.0 system that integrates library resource organization with user-librarian interaction by the 
merger of information resources and Web 2.0 services. The features discussed are beneficial to end-users and librarians alike. While products like CampusGuides expand upon the features of LibGuides, complete Library 2.0 systems are still being developed. These systems will need to have single log-ins that encompass subject guides, integrated library catalog systems, authentication to external library resources and other library systems.

\section{End Notes}

1. Michael E. Casey and Laura C. Savastinuk, "Library 2.0: Service for the Next Generation Library," Library Journal, 131 no. 14 (9/1/2006,): 41-42.

${ }^{2}$ Michael E. Casey, "Librarians Without Borders," LibraryCrunch. Retrieved on 3/4/2010 from http://www.librarycrunch.com/2005/09/librarians_without_borders.html

3. Jill M. Sodt and Terri Pederson Summey, "Beyond the Library of Walls: Using Library 2.0 Tools to Research Out to All Users," Journal of Library Administration, 49, no. 11 (Nov 2009): 98.

${ }^{4}$ Ellie Bushhousen, "LibGuides," Journal of the Medical Library Association, 97 no. 1 (Jan 2009): 65-67.

${ }^{5}$ Jeffrey Pomerantz, "Collaboration as the Norm in Reference Work," Reference and User Services Quarterly, 6 no. 1 (Fall 2006): 51.

${ }^{6}$ Ibid, 53.

7. Becky Gibson, "Enabling an Accessible Web 2.0," in Proceedings of the 2007 international crossdisciplinary conference on Web accessibility (W4A) 1997: vol. 225, by ACM International Conference Proceeding Series, Vol. 225, Banff, Canada Pages: $1-6$.

${ }^{8}$ Email, Slaven Zivkovic of Springshare, Email to author, December 15, 2009.

${ }^{9}$ Richard Bernier and Amy Harshbarger, "Logan Library Electronic Resources Evaluation, September 2007-May 2008,” (Terre Haute, IN: Rose-Hulman Institute of Technology, Feb 2009, internal report), 9. 